\title{
EVALUATION OF TIME SERIES TANDEM-X DIGITAL ELEVATION MODELS
}

\author{
M. Jain*, R. Deo, V. Kumar, Y. S. Rao \\ Centre of Studies in Resources Engineering, Indian Institute of Technology Bombay, Powai, Mumbai 400076, INDIA. \\ minaaljaingnr@gmail.com
}

Commission VIII, WG VIII/5

KEY WORDS: Synthetic Aperture Radar Interferometry, Digital Elevation Model, Fusion, TanDEM X, Time series data, Evaluation

\begin{abstract}
:
Digital Elevation Model (DEM) is an important input for geo-spatial analysis. For various applications like flood management, ortho rectification of remote sensing images, navigation, architectural works, defence, etc., high resolution DEM is required. TanDEM-X mission was launched in 2010 to obtain high resolution global DEM with HTRI-3 standard. SAR interferometry (InSAR) technique is used for DEM generation from TanDEM-X SAR data. The accuracy of DEM depends on many parameters like height ambiguity, incidence angle, polarization, etc. In this study, time series TanDEM-X data spanning over 3 years, had processed for generating DEM at the spatial resolution of $6 \mathrm{~m}$ and their accuracy had studied using DGPS elevation data and SRTM $90 \mathrm{~m}$ DEM. The products generated during DEM generation process are DEM, precision (or height error), coherence, layover and shadow images. Using weighted average fusion technique, ascending and descending DEMs are fused for improving the quality of DEM and to reduce invalid pixels corresponding to layover and shadow areas. Results from time series data were analysed and found RMSE error of fused DEMs is in the range of $2 \mathrm{~m}$ to $4 \mathrm{~m}$, while individual DEM has accuracy of $3 \mathrm{~m}$ to $6 \mathrm{~m}$ with respect to DGPS elevation data. Fused DEMs are having high accuracy as well as less voids. The reduction of voids by fusion, ranges from 40 to $85 \%$ in different combinations of data.
\end{abstract}

\section{INTRODUCTION}

DEM is an important input for geo-spatial analysis, particularly in flood management, ortho-rectification of remote sensing images, navigation, architectural works, defence, etc. At present, freely available global DEMs are from SRTM and ASTER at spatial resolution of $90 \mathrm{~m}$ and $30 \mathrm{~m}$ respectively. For many applications, high resolution DEMs are required. In 2010, TanDEM-X mission was launched to obtain high resolution global DEM at the spatial resolution of $12 \mathrm{~m}$ with an absolute vertical accuracy of $10 \mathrm{~m}$ and relative accuracy of $2 \mathrm{~m}$ (Moreira et al., 2004, 2008; Krieger et al., 2005; Toutin and Gray, 2000). According to Weber et al. (2006), there is a global need of HRTI-3 standard DEM having better vertical accuracy, consistency and global access. It is also important to know the quality and accuracy of DEMs because DEM quality can affects the quality of applications in which they are used. The quality of the DEM can be improved by fusing ascending and descending DEMs (Sansosti et al., 2000).

In this study, DEMs are generated from time series TanDEM-X data over three years period i e., 2011 to 2013 over Mumbai area, later these DEMs were fused and analysed. Weighted average fusion technique is used for fusion of DEMs. The accuracy of this fused DEMs depend on the parameters of input DEM like incidence angle, polarization, baseline, etc., which are considered for the selection of DEMs to be fused. All generated DEM's accuracy were studied using DGPS elevation data and SRTM DEM.

\section{STUDY AREA AND DATA SETS}

Mumbai is chosen as test area for this study. Mumbai covers varying land features such as reserved forest, mangroves, grass lands, wetlands, agriculture lands, and built-up area from high rise buildings to slums. Mumbai lies on the western coast of India

\footnotetext{
${ }^{*}$ Corresponding author.
}

and has total area of $603.4 \mathrm{~km}^{2}$. Elevation in this area vary from $15 \mathrm{~m}$ average in south Mumbai to $450 \mathrm{~m}$ in hilly region of north Mumbai above the mean sea level. The hilly terrain has thick to sparse vegetation cover and affects the DEM accuracy. The test area gives an opportunity to analyse and evaluate DEM with various land features.

For high resolution DEM generation and evaluation, TanDEM-X SAR Coregistered Single Look Slant Range Complex (CoSSC) data over Mumbai was acquired during 2011 to 2013. As the Mumbai area is selected for our research, DLR has been acquiring data under A.O. programme. 11 data sets have been received for our application and they are listed in Table 1 with their sensor parameters like incidence angle, direction of system pass, baseline and Height of Ambiguity (HoA).

\begin{tabular}{l|c|c|c|r|r}
\hline $\begin{array}{l}\text { Date of } \\
\text { acquisition }\end{array}$ & $\begin{array}{c}\text { Inc. } \\
\text { angle }\end{array}$ & $\begin{array}{c}\text { Polar } \\
\text {-ization }\end{array}$ & Pass & $\begin{array}{r}\text { Baseline } \\
(\mathrm{m})\end{array}$ & HoA \\
\hline $22-04-11$ & 33.8 & $\mathrm{VV}$ & Desc. & 101.4 & 51.4 \\
$08-05-11$ & 46.1 & $\mathrm{VV}$ & Asc. & 161.5 & 49.2 \\
$03-12-11^{*}$ & 46.2 & $\mathrm{HH}$ & Asc. & 85.8 & 92.8 \\
27-05-12 G & 45.8 & $\mathrm{HH}$ & Asc. & 245.8 & 32.9 \\
09-09-12* & 33.8 & $\mathrm{HH}$ & Desc. & 125.2 & 41.8 \\
25-11-12* & 33.7 & $\mathrm{HH}$ & Desc. & 73.2 & 72.6 \\
08-01-13 G & 29.9 & $\mathrm{HH}$ & Asc. & 132.9 & 34.1 \\
19-01-13 G & 33.3 & $\mathrm{HH}$ & Desc. & 36.8 & 151.6 \\
26-02-13* & 46.2 & $\mathrm{HH}$ & Asc. & 97.2 & 82.0 \\
29-02-13* & 46.2 & $\mathrm{HH}$ & Asc. & 61.9 & 131.9 \\
18-09-13* & 33.7 & $\mathrm{HH}$ & Desc. & 114.9 & 45.7 \\
\hline
\end{tabular}

Table 1: TanDEM-X data sets acquired on different dates at different look angle, baselines and polarizations.

Datasets in Table 1 are data acquired for experimental purpose as well as for Global DEM generation purpose (marked with $\mathrm{G}) . *$ symbol marked datasets are used for fusing ascending and descending DEMs in DEM fusion technique in this study. 
DGPS points of around 25 have been used to evaluate the accuracy of generated and fused DEMs. SRTM DEM over the area is used in TanDEM-X DEM generation procedure as well as for DEM evaluation.

\section{METHODOLOGY}

The SAR Interferometry (InSAR) technique is used to process TanDEM-X data sets and generating DEM at spatial resolution of $6 \mathrm{~m}$. Interferogram generation, flat terrain removal, phase unwrapping, phase to elevation conversion and geocoding are various steps in TanDEM-X InSAR DEM generation technique. Coregistration is the first step in InSAR DEM generation but in TanDEM-X processing, we have coregistered data, therefore this step was skipped. With DEM as final product, other products generated during InSAR processing are precision (height error), coherence, layover and shadow images. SRTM DEM is used for flat terrain removal in processing of TanDEM-X SAR data. The detailed flow chart of the InSAR procedure is shown in Figure 1.

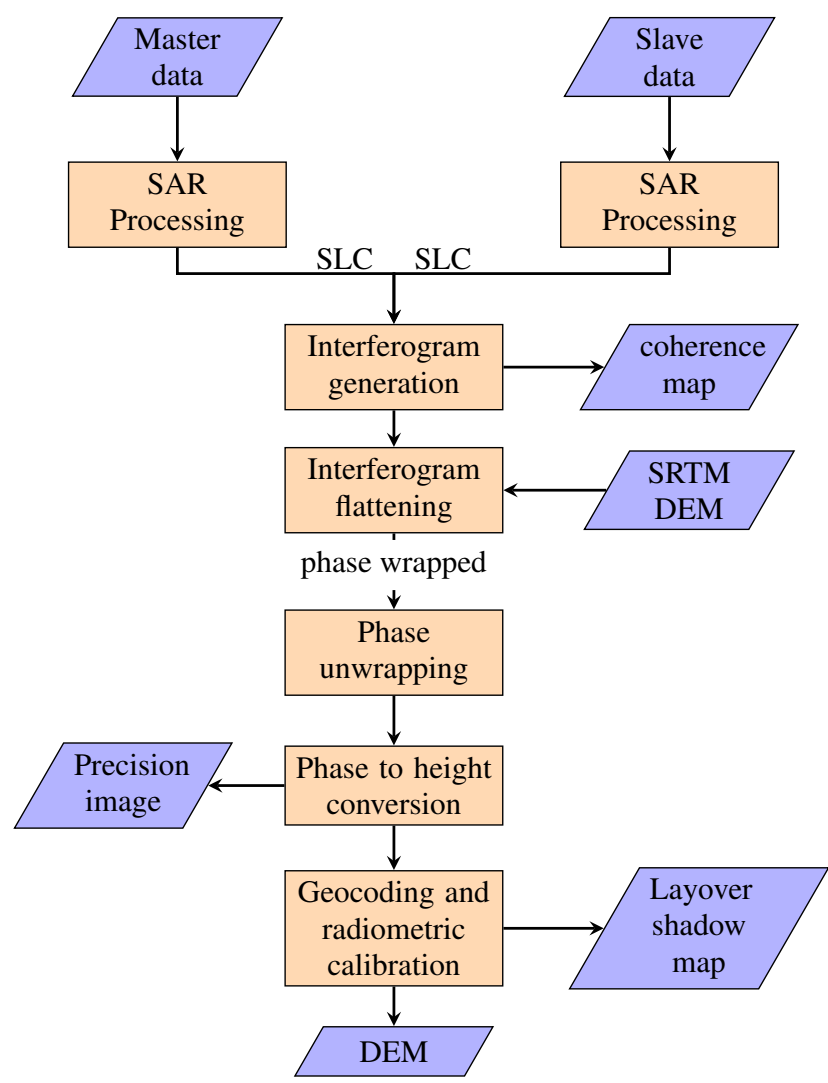

Figure 1: Flow chart of TanDEM-X InSAR DEM generation process

All 11 datasets are processed and DEMs are produced. * marked datasets of Table 1 are fused and their different combinations are carried out and analysed. 3 datasets of each ascending and descending pass are chosen and all nine combination that are possible in between them, are fused. They have very similar incidence angle for ascending pass $\left(46^{\circ}\right)$ and descending pass $\left(33^{\circ}\right)$ but different HoA. In fusion, pixel value is selected from ascending and descending DEM pixel values. Ascending DEM pixel value, descending DEM pixel value, weighted average of both DEM's pixel values and NAN are possible values for fused DEM pixel in different scenarios. The DEM accuracy with respect to their characteristics like HoA and incidence angle are throughly checked. Deo et al. (2014) has given the description of the fusion technique.

Coherence is a function of systemic spatial de-correlation and scene de-correlation that takes place between master and slave acquisitions. It's value ranges from 0 to 1 . It is a ratio between coherent and incoherent summations. It is used to determine the quality of measurement. For 2 coregistered complex SAR images $S_{1}$ and $S_{2}$, interferometric coherence $(\gamma)$ is given as:

$$
\gamma=\frac{\left|\Sigma s_{1}(x) \cdot s_{2}(x)^{*}\right|}{\sqrt{\Sigma\left|s_{1}(x)\right|^{2} \cdot \Sigma\left|s_{2}(x)\right|^{2}}}
$$

Precision is derived from parameters such as coherence, baseline and wavelength. Precision is an estimate of the measurement precision. Lower the precision value, the higher the measurement precision. Formula used for precision calculation is:

$$
p=\sqrt{\frac{1-\gamma^{2}}{2 \gamma^{2}}} \frac{\lambda R \sin \vartheta}{4 B \pi}
$$

where,

$\mathrm{p}=$ precision value

$\gamma=$ coherence value

$\lambda=$ wavelength

$B=$ baseline

$\mathrm{R}=$ slant range

$\vartheta=$ local incidence angle

As both ascending and descending DEMs have different HoA, their height error value (precision) is taken as reference along with layover shadow image, for the selection of fused DEM pixel value. The precision value at $90 \%$ cumulative frequency for both input DEMs is found using statistical tool and maximum of input DEM's HoA value is considered as Precision Threshold (PTH) for fusing the DEMs. (Deo et al., 2014)

- NAN : If both DEM's $\mathrm{n}^{\text {th }}$ pixel has layover shadow or if one has layover shadow and other has precision greater than threshold or in case of none has layover shadow but both have precision value greater than PTH, then fused DEM has NAN value for that pixel.

- Ascending or descending DEM value : If any input DEM's $\mathrm{n}^{\text {th }}$ pixel has no layover shadow and it's precision value is less than PTH while other DEM has layover shadow or precision value greater than PTH value, then fused DEM has first DEM's pixel value.

- Weighted Sum : If both DEM's $n^{\text {th }}$ pixel has no layover shadow and also precision value is less than PTH, then fused DEM has weighted sum of both input DEM's pixel value.

The weighted average height value $\hat{h}$ is then calculated using the maximum likelihood estimation as below:

$$
\hat{h}=\sum_{i=1}^{2} w_{i} h_{i}
$$

where,

$\mathrm{w}_{i}=$ Weight $\mathrm{w}$ assigned to $\mathrm{i}^{\text {th }}$ DEM pixel,

$\mathrm{h}_{i}=$ Height value $\mathrm{h}$ of $\mathrm{i}^{\text {th }}$ DEM pixel. 
The weights for both DEMs have been derived from the precision map as

$$
w_{i}=\frac{\frac{1}{\sigma_{h, i}^{2}}}{\sum_{i=1}^{N} \frac{1}{\sigma_{h, i}^{2}}}
$$

where,

$\sigma_{h, i}=$ Standard deviation of $\mathrm{i}^{\text {th }} \mathrm{DEM}$ at any pixel.

Water mask is created using ArcGIS online base map and one of precision images from TanDEM-X data for masking out water areas in accuracy assessment. Both raw DEMs and fused DEMs are analysed for their accuracy. The precision value and fused DEM elevation at DGPS locations are extracted for comparison. Validation of ascending, descending, and fused DEMs have been done using DGPS elevation data and also SRTM $90 \mathrm{~m}$ DEM.

In the fusion, if input ascending DEM has $\mathrm{x} \%$ invalid pixels and descending DEM has y\% invalid pixels and the fused DEM has f\% invalid pixel, then Invalid Pixel Reduced (IPR) ratio is given by the ratio of minimum of input DEM invalids ( $x$ and $y$ ) and fused DEM invalids (f), as shown below:

$$
I P R=\frac{\min (x, y)}{f}
$$

IPR shows improvement factor in fused DEM, higher the ratio more the improvement. The percentage improvement after fusion is given by:

$$
\text { Improvement }=1-\frac{1}{I P R} * 100 \%
$$

In this way, IPR shows degree of improvement for any ascending and descending DEM.

\section{ANALYSIS AND RESULTS}

\subsection{TanDEM-X DEM generated from various datasets}

For all datasets mention in Table 1, DEMs were generated using SAR Interferometric DEM generation procedure with the help of SARscape 5.0 tool. All generated DEMs are having spatial resolution of 6 meters. Ascending and descending DEM precision maps are shown in Figure 2.

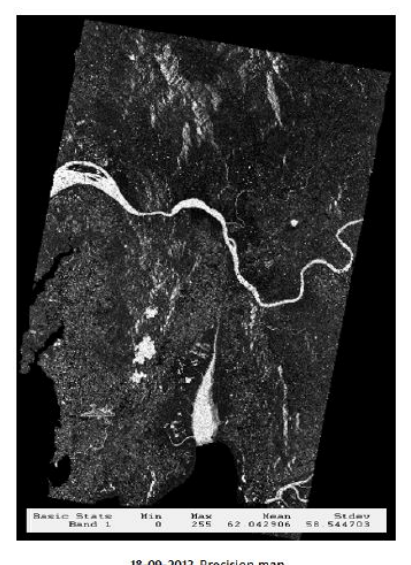

18092013 precision map

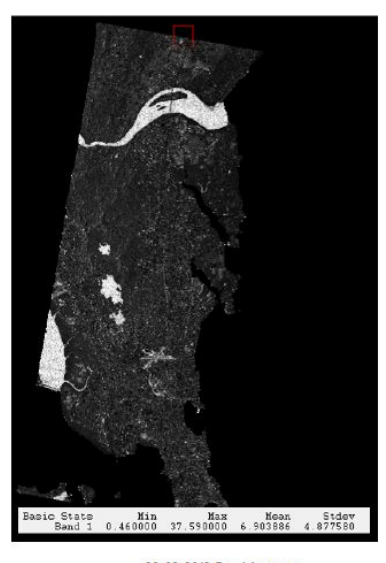

29-02-2013 Precision map
Figure 2: Precision map of Ascending (29-02-13) and Descending (09-09-12) DEM.

For accuracy analysis of raw DEMS, RMSE of each raw DEM is calculated using their elevation and DGPS elevation data. DGPS elevation data over 25 points in Mumbai area are acquired. In Figure 3, these points are shown as green points overlaid over SAR intensity image of Mumbai.

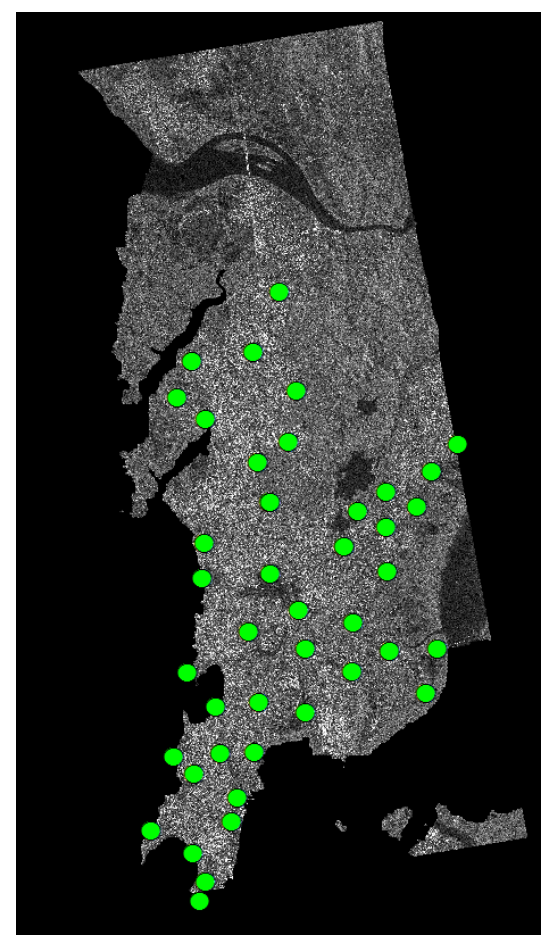

Figure 3: DGPS location in Mumbai overlaid on TanDEM-X intensity image. (26-01-13)

The RMSE found in every DEM with respect to DGPS elevation data and SRTM elevation data, are tabulated in Table 2 with it's dataset characteristics for analysis.

\begin{tabular}{r|r|r|r|r|r}
\hline $\begin{array}{r}\text { Date of } \\
\text { DEM }\end{array}$ & $\begin{array}{r}\text { Baseline } \\
(\mathrm{m})\end{array}$ & HoA & $\begin{array}{r}\text { Mean Diff. } \\
\text { (DGPS) }\end{array}$ & \multicolumn{2}{|c}{ RMSE } \\
(DGPS) & (SRTM) \\
\hline $22-04-11$ & 101.4 & 51.4 & -2.58 & 4.18 & 4.22 \\
$08-05-11$ & 161.5 & 49.2 & 1.64 & 3.05 & 3.14 \\
$03-12-11$ & 85.8 & 92.8 & 0.85 & 3.17 & 3.29 \\
$27-05-12$ & 245.8 & 32.9 & 1.36 & 3.50 & 3.90 \\
$09-09-12$ & 125.2 & 41.8 & -0.72 & 3.46 & 3.38 \\
$25-11-12$ & 73.2 & 72.6 & 3.94 & 5.50 & 5.73 \\
$08-01-13$ & 132.9 & 34.1 & 1.58 & 3.53 & 3.39 \\
$19-01-13$ & 36.8 & 151.6 & -1.99 & 5.37 & 5.82 \\
$26-02-13$ & 97.2 & 82.0 & -0.32 & 4.65 & 4.05 \\
$29-02-13$ & 61.9 & 131.9 & 1.01 & 3.67 & 4.36 \\
$18-09-13$ & 114.9 & 45.7 & 0.92 & 3.37 & 3.41 \\
\hline
\end{tabular}

Table 2: Data sets characteristics and DEM RMSE w.r.t. DGPS data and SRTM data.

Baseline for these datasets vary and hence HoA. Although it has different HoA, RMSE deviation is not much different for the generated DEMs. Mean of the difference between TanDEM-X DEM and DGPS elevation data is also given in Table 2. Elevation difference between DGPS and generated DEM elevation varies from $0 \mathrm{~m}$ to $17 \mathrm{~m}$ for flat to hilly terrain. The data acquired on 08-05-11 and 03-12-11 in ascending pass gives lower RMSE. The elevation difference for this data sets are $0 \mathrm{~m}$ to $8 \mathrm{~m}$ with respect to DGPS elevation data. From Table 2, it can be concluded that higher the HoA, larger the error in generated raw DEM. Therefore, HoA can assist in dataset selection for DEM generation. For DEM fusion, input with lower RMSE are preferred for generating more accurate DEM. 


\begin{tabular}{r|r|r|r|r}
\hline $\begin{array}{r}\text { Date of } \\
\text { Acquisition }\end{array}$ & $\begin{array}{r}\text { Baseline } \\
(\mathrm{m})\end{array}$ & HoA & $\begin{array}{r}\text { Mean } \\
\text { Precision (m) }\end{array}$ & $\begin{array}{r}\text { RMSE } \\
\text { Precision (m) }\end{array}$ \\
\hline $22-04-11$ & 101.4 & 51.4 & 4.04 & 5.05 \\
$08-05-11$ & 161.5 & 49.2 & 3.87 & 4.32 \\
$03-12-11$ & 85.8 & 92.8 & 8.02 & 9.08 \\
$27-05-12$ & 245.8 & 32.9 & 2.38 & 2.81 \\
$09-09-12$ & 125.2 & 41.8 & 3.50 & 3.91 \\
$25-11-12$ & 73.2 & 72.6 & 5.61 & 6.80 \\
$08-01-13$ & 132.9 & 34.1 & 3.36 & 3.95 \\
$19-01-13$ & 36.8 & 151.6 & 10.27 & 10.98 \\
$26-02-13$ & 97.2 & 82.0 & 6.63 & 7.60 \\
$29-02-13$ & 61.9 & 131.9 & 10.59 & 13.63 \\
$18-09-13$ & 114.9 & 45.7 & 3.43 & 3.83 \\
\hline
\end{tabular}

Table 3: Mean and RMSE of precision (Height error) value at DGPS locations for different data sets.

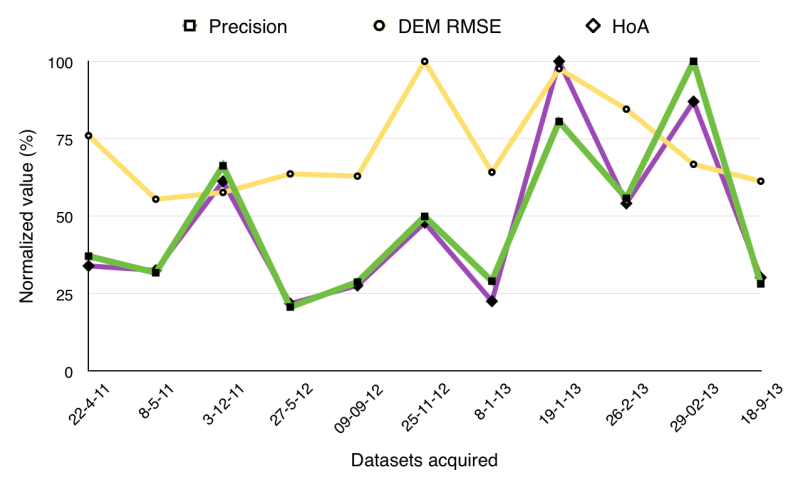

Figure 4: Normalized RMSE for various raw DEMs with their precision and HoA.

Mean and RMS of precision image values at DGPS locations from each dataset are tabulated in Table 3 and shown in Figure 4. DEM obtained using May 27, 2012 dataset has least HoA of 32.9 m, whereas Feb. 29, 2013 dataset and Jan. 19, 2013 dataset have larger HoA of more than $120 \mathrm{~m}$. The precision RMSE for these datasets are $2.81 \mathrm{~m}, 13.63 \mathrm{~m}$ and $10.98 \mathrm{~m}$ respectively. Figure 4 shows normalized values of HOA, RMS of precision values and RMSE in DEM elevation for different data sets. Precision and HoA follow the same trend. RMSE of DEM does not change as similar to HoA or precision, but slightly increases with increasing $\mathrm{HoA}$ and precision.

\subsection{TanDEM-X DEM Fusion Analysis}

Figure 5 shows common area for all datasets for fusing ascending and descending DEM which are indicated by * symbol in Table 1 . For fusion, 3 ascending and 3 descending DEMs as mentioned in methodology are selected and all possible combinations are examined and as a result, nine fused DEMs are generated. All fused DEMs are analysed. The RMSE error of fused DEMs with reference to DGPS data, Invalid Pixel Reduced (IPR) ratio, invalid pixels percentage in all DEMs w.r.t. fusion threshold are shown in Table 4.

Input DEMs and fused DEMs invalid pixel percentage, RMSE in fused DEM elevation and respective IPR ratio are plotted in Figure 6. Here fused DEM invalid pixels percentage ranges from 0.13 to $2.1 \%$, whereas input DEM has invalid pixels in the range of $0.3 \%$ to $14.6 \%$. Since, all ascending DEMs and descending DEMs have same target area and incidence angle of $46.2^{\circ}$ and $33.7^{\circ}$, so it can be assumed that in this study, the fusion procedure is independent of incidence angle and depends on HoA mainly.

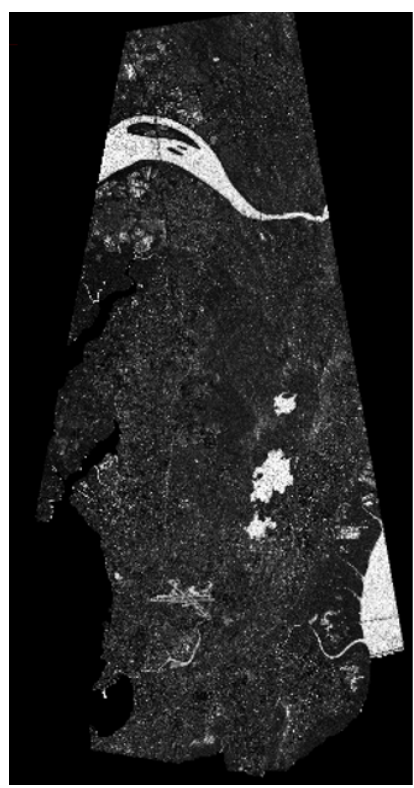

Figure 5: Precision image of common area for DEM fusion.

\begin{tabular}{|c|c|c|c|c|c|c|c|}
\hline \multirow[t]{2}{*}{ F.N. } & \multirow{2}{*}{$\begin{array}{l}\text { DEMs } \\
\text { Fused }\end{array}$} & \multicolumn{3}{|c|}{ Dem Invalid Pixels (\%) } & \multirow[t]{2}{*}{ IPR } & \multirow{2}{*}{$\begin{array}{l}\text { Improve } \\
\text { ment }(\%)\end{array}$} & \multirow[t]{2}{*}{ RMSE } \\
\hline & & ASC & DSC & Fused & & & \\
\hline 1 & $\begin{array}{l}18-09-13 \\
26-02-13\end{array}$ & 6.96 & 7.89 & 1.45 & 4.80 & 79.17 & 2.26 \\
\hline 2 & $\begin{array}{l}18-09-13 \\
03-12-11\end{array}$ & 7.33 & 6.96 & 1.41 & 4.93 & 79.71 & 2.15 \\
\hline 3 & $\begin{array}{l}18-09-13 \\
29-02-13\end{array}$ & 8.18 & 3.59 & 1.30 & 2.76 & 63.76 & 2.40 \\
\hline 4 & $\begin{array}{l}25-11-12 \\
26-02-13\end{array}$ & 12.11 & 10.50 & 2.10 & 5.00 & 80.0 & 3.69 \\
\hline 5 & $\begin{array}{l}25-11-12 \\
03-12-11\end{array}$ & 12.44 & 9.63 & 2.02 & 4.77 & 79.00 & 3.69 \\
\hline 6 & $\begin{array}{l}25-11-12 \\
29-02-13\end{array}$ & 13.30 & 8.47 & 1.63 & 5.20 & 80.76 & 4.33 \\
\hline 7 & $\begin{array}{l}09-09-12 \\
26-02-13\end{array}$ & 14.64 & 5.21 & 0.82 & 6.35 & 84.25 & 2.27 \\
\hline 8 & $\begin{array}{l}09-09-12 \\
03-12-11\end{array}$ & 10.77 & 1.61 & 0.33 & 4.87 & 79.45 & 2.28 \\
\hline 9 & $\begin{array}{l}09-09-12 \\
29-02-13\end{array}$ & 13.20 & 0.31 & 0.13 & 2.38 & 57.90 & 2.50 \\
\hline
\end{tabular}

Table 4: Fusion of various combination of date sets and RMSE error of fused DEMs with reference to DGPS data.

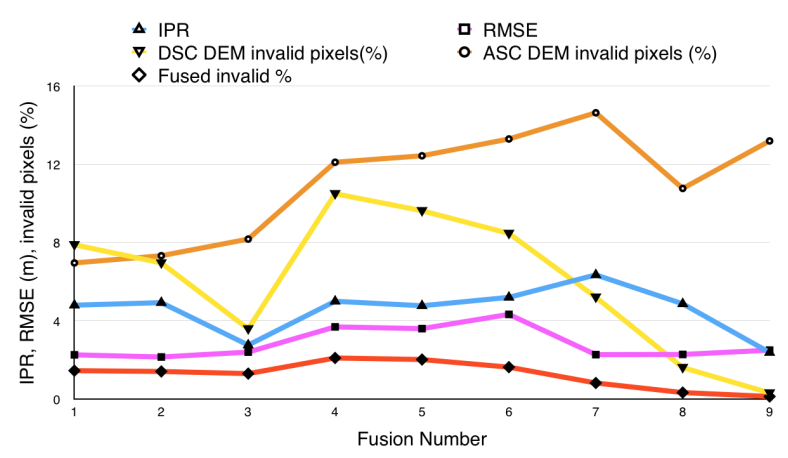

Figure 6: Invalid pixels of ascending, descending, fused, IPR and RMSE of fused DEMs.

In Table 5 and Figure 7, invalid pixels \% and the RMSE in fused DEMs are plotted against the difference of input's HoAs of each fusion. It has been observed that increase in HoA's difference in between the input DEMs, reduces the RMSE and invalid pixels $\%$ values in fused DEM. Six out of nine fused DEM follows this trend, while Fusion No. (F.N.) 6, 9 and 2 shows quite high 


\begin{tabular}{r|r|r|r|r}
\hline F.N. & $\begin{array}{r}\text { Asc. DEM } \\
\text { HoA }\end{array}$ & $\begin{array}{r}\text { Dsc. DEM } \\
\text { HoA }\end{array}$ & $\begin{array}{r}\text { HoA } \\
\text { difference }\end{array}$ & $\begin{array}{r}\text { Fused DEM } \\
\text { invalids (\%) }\end{array}$ \\
\hline 1 & 82.0 & 45.7 & 36.3 & 1.45 \\
2 & 92.8 & 45.7 & 47.1 & 1.41 \\
3 & 131.9 & 45.7 & 86.2 & 1.30 \\
4 & 82.0 & 72.6 & 9.4 & 2.10 \\
5 & 92.8 & 72.6 & 20.2 & 2.02 \\
6 & 131.9 & 72.6 & 59.3 & 1.63 \\
7 & 82.0 & 41.8 & 40.2 & 0.82 \\
8 & 92.8 & 41.8 & 51 & 0.33 \\
9 & 131.9 & 41.8 & 90.1 & 0.13 \\
\hline
\end{tabular}

Table 5: HoA of input, RMSE and HoA difference of fused DEMs.

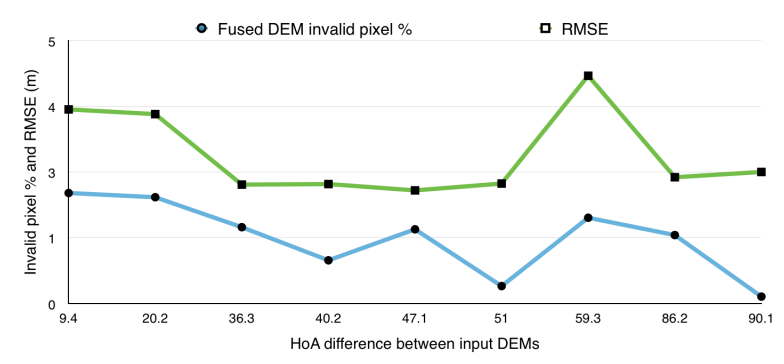

Figure 7: Fused DEM invalid pixels count with respect to difference in HoA of input DEMs

variations. Due to different input HoAs and PTH dependency on higher HoA, PTH increases with increase in HoA in input DEM, which reduces number of invalid pixels in lower HoA input and leads to decreases in fused DEM invalid pixel count. Further study on fusion with different thresholds and incidence angles are required.

Ascending, descending and fused DEM for F. N. 7 is shown in Figure 8 as colour shaded map with pixels having layover shadow and precision greater than threshold as invalid voids. Considerable reduction of voids are seen in fused DEM $(84 \%)$.

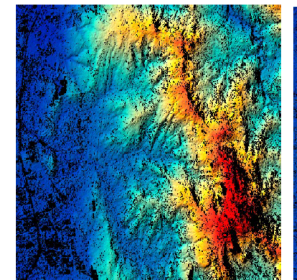

(a) Ascending DEM

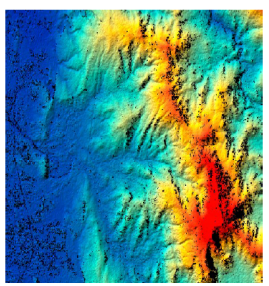

(b) Descending DEM

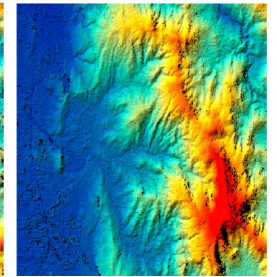

(c) Fused DEM
Figure 8: ArcScene view of Ascending DEM subset with voids. same trend, HoA can assist in preliminary analysis for dataset selection in DEM generation as well as for DEM fusion. It is also observed that HoA's difference lying between 35 to $50 \mathrm{~m}$ range had shown a better reduction in void's count. Fusion of datasets with different incidence angles and different PTH for each input can be extension of this study.

\section{ACKNOWLEDGEMENT}

Authors thank DLR, Germany for providing TanDEM-X datasets under AO proposal id XTI_VEGE0635. Thanks are also due to SARMAP for providing the evaluation version of SARScape software.

\section{References}

Deo, R., Rossi, C., Eineder, M., Fritz, T. and Rao, Y. S., 2014. Fusion of ascending and descending pass raw tandem-x dem. Proc. IGARSS, Quebec, Canada; Proceedings pp. 21-24.

Krieger, G., Hajnsek, I., Fiedler, H., Hajnsek, I., Eineder, M., Werner, M. and Moreira, A., 2005. Tandem-x: Mission concept and performance analysis. Geoscience and Remote Sensing Symposium, IGARSS '05. Proceedings, IEEE International, vol 7, pp. 4890 - 4893.

Moreira, A., Krieger, G., Fiedler, H., Hajnsek, I., Younis, M., Zink, M. and Werner, M., 2008. Advanced interferometric sar techniques with tandem-x. Radar Conference, RADAR '08, IEEE,at Rome, Italy pp. 1-5.

Moreira, A., Krieger, G., Hajnsek, I., Hounam, D., Werner, M., Riegger, S. and Settelmeyer, E., 2004. Tandem-x: A terrasar- $\mathrm{x}$ add-on satellite for single-pass sar interferometry. Geoscience and Remote Sensing Symposium, 2004. IGARSS '04. Proceedings. IEEE International, vol 2, pp. 1000-1003.

Sansosti, E., Lanari, R., Fornaro, G., Franceschetti, G., Tesauro, M., Puglisi, G. and Coltelli, M., 2000. Digital elevation model generation using ascending and descending ers-1/ers-2 tandem data. International Journal of Remote Sensing, vol 20, pp. Issue 8, 1527-1547.

Toutin, T. and Gray, L., 2000. State-of-the-art of elevation extraction from satellite sar data. ISPRS Journal of Photogrammetry and Remote Sensing, vol 55, pp. 13-33.

Weber, M., Herrmann, J., Hajnsek, I. and Moreira, A., 2006. Terrasar-x and tandem-x: Global mapping in $3 \mathrm{~d}$ using radar. Proc. Second International Workshop on "The Future of Remote Sensing", Antwerp, Belgium , ISPRS Intercommission Working Group I/V Autonomous Navigation,36-1/W44.

\section{CONCLUSION}

From the time series analysis within the span of 3 years, it has been observed that TanDEM-X DEMs generated in this study have better accuracy than the specified values for TanDEM-X global DEM with HRTI-3 standard and have similar accuracy as TanDEM-X proposed regional DEMs with HTRI-4 standard. RMS errors in ascending and descending DEM varies from 3 to $6 \mathrm{~m}$ while by fusing ascending and descending DEM, the error reduces by 2 to $4 \mathrm{~m}$ and invalid pixel count reduced upto $80 \%$ with respect to input DEM values. As the HoA and RMSE follows 